\title{
Latent class analysis of dietary restraint in mother-adolescent dyads
}

\author{
Análisis de clases latentes de restricción alimentaria en díadas \\ madre-adolescente
}

\begin{abstract}
The objectives of this study were to identify adolescent profiles based on their dietary restraint behavior. A sample of 470 mothers with one child between 10 and 17 years of age were surveyed in Chile. Questionnaires included the Revised Restraint Scale, Satisfaction with Life Scale, Satisfaction with Food-related Life scale, Satisfaction with Family Life scale and the Adapted Healthy Eating Index. The results of the Latent Class Analysis yielded two classes: dieters and non-dieters. Dieters had a higher mean age, higher proportion of overweight and obesity and lower scores on the satisfaction with life and food-related life. Families from the dieters class had a lower frequency of family dinners. Their mothers had higher weight fluctuation and rates of obesity. The results suggest that interventions aimed at reducing overweight/obesity and dietary restraint in adolescents and intended to improve adolescent subjective well-being must include both the mother and the adolescent, regardless of sex.

Keywords: Adolescents; Dietary restriction; Family; Food; Mothers; Life satisfaction; Sex.
\end{abstract}

\section{RESUMEN}

Los objetivos de este estudio fueron identificar perfiles de adolescentes basados en su comportamiento de restricción alimentaria. Se encuestó a una muestra de 470 madres con un hijo entre 10 y 17 años en Chile. Los cuestionarios incluyeron la Escala Revisada de Restricción, la Escala de Satisfacción con la Vida, la Escala de Satisfacción con la Alimentación, la Escala de Satisfacción con la Vida Familiar y el Índice de Alimentación Saludable Adaptado. Los resultados del análisis de clases latentes arrojaron dos tipos: dietantes y no dietantes. Los dietantes tuvieron una edad media más alta, mayor proporción de sobrepeso y obesidad y puntuaciones más bajas en la satisfacción con la vida y con la alimentación. Las familias de los dietantes tuvieron una menor frecuencia de cenas familiares. Sus madres tuvieron una mayor fluctuación de peso y tasas de obesidad. Los resultados sugieren que las intervenciones dirigidas a reducir la obesidad/sobrepeso y la restricción alimentaria en adolescentes y destinadas a mejorar el bienestar subjetivo
Berta Schnettler ${ }^{1,2,5,6^{*}}$, Edgardo Miranda-Zapata ${ }^{3}$, Germán Lobos ${ }^{4,5}$, María Lapo ${ }^{5}$, Marianela Denegri ${ }^{6,7}$, Clementina Hueche ${ }^{6}$.

1. Universidad de La Frontera, Faculty of Agricultural Sciences and Forestry, Temuco, Chile. 2. Universidad de La Frontera, Scientific and Technological Bioresource Nucleus (BIOREN-UFRO), Temuco, Chile.

3. Universidad de La Frontera, Scientific and Technological Nucleus in Social Sciences, Research Laboratory in Applied Social Sciences (LICSA), Temuco, Chile. 4. Universidad de Talca, Faculty of Business and Economics, Interdisciplinary Excellence

Research Program on Healthy Aging (PIEI-ES), Talca, Chile. 5. Universidad Católica de Santiago de Guayaquil, Guayaquil, Ecuador. 6. Universidad de La Frontera, Scientific and Technological Nucleus in Social Sciences, Center for Excellence in Economic and Consumer Psychology, Temuco, Chile.

7. Universidad de La Frontera, Faculty of Education, Social Sciences and Humanities, Temuco, Chile.

\begin{abstract}
*Corresponding Author: Berta Schnettler, Faculty of Agricultural Sciences and Forestry, Universidad de La Frontera, PO Box 54-D, Temuco, Chile. Email: berta.schnettler@ufrontera.cl
\end{abstract}

Este trabajo fue recibido el 22 de octubre de 2019. Aceptado con modificaciones: 08 de enero de 2020. Aceptado para ser publicado: 04 de abril de 2020.

de los adolescentes deben incluir tanto a la madre como al adolescente, independientemente del género.

Palabras clave: Adolescentes; Alimentación; Familia; Género; Madres; Restricción alimentaria; Satisfacción con la vida.

\section{INTRODUCTION}

"Dietary restraint behavior refers to conscious attempts to reduce food intake to control body weight" ${ }^{\prime \prime}$. Although it has been reported that restraint may be an effective strategy in controlling body weight ${ }^{2}$, some studies have indicated that excessive restriction may have negative outcomes, such as overeating and weight gain ${ }^{1,3}$. 
Different individual and psychosocial variables may impact dieting behavior in childhood and adolescence ${ }^{4}$, including sociocultural pressure to be thin ${ }^{4,5,6}$ and individual characteristics such as increased weight status or body mass index (BMI). Forrester-Knauss et $\mathrm{al}^{7}$ and Balantekin et $\mathrm{al}^{4}$ stressed that a higher BMI may cause restricted eating. This is especially important as the global number of children and adolescents (5-19 years old) who are obese has grown tenfold between 1975 and 2016. In 2016, 213 million children and adolescents were overweight ${ }^{8}$.

Although several factors impact adolescent eating behaviors, family is an important influence ${ }^{9,10,11}$. Increasing evidence indicates that a higher frequency of family meals are associated with a healthy diet ${ }^{12}$, a lower likelihood of obesity or being overweight ${ }^{13}$, better family interaction and communication $^{12}$ and increased adolescent well-being 3,13,14,15. At the same time, it has been reported that a low frequency of family meals may predict extreme weight control behaviors in adolescents $s^{6,12}$. These behaviors negatively affect adolescent diet quality ${ }^{13,16}$ and well-being. In addition, some studies have shown that parents can promote the development of child dieting behavior by conveying to the child that being thin is important to his or parents, by verbally encouraging dieting or by modeling their own dieting behaviors ${ }^{5}$. Controlling food-related parenting practices such as food restriction may also be used ${ }^{17}$. Although it is well established that both mothers and fathers influence their children's eating behavior, it is also well known that their influence differs ${ }^{11}$. Some studies have shown that both parents are engaged in practices that promote healthy eating and an adequate BMI in their adolescent children ${ }^{6,12}$ while others have suggested that mothers exert greater influence on their daughters and fathers on their sons ${ }^{10}$. There is also evidence suggesting that the mother's role is more relevant ${ }^{5,6,11,12,18,19}$.

Some studies have reported that dietary restraint is related to lower levels of life satisfaction in adolescents and emerging adults ${ }^{20}$ while others have reported no association between dietary restraint and life satisfaction ${ }^{21}$. Similarly, dietary restraint has been also associated with lower levels of satisfaction in the food domain in adolescents and university students $\mathrm{s}^{20,22,23}$. In addition, researchers have suggested that individuals with eating disorders are impaired in other important domains of their lives, such as in social relationships ${ }^{22}$. This may be relevant for adolescents as family relationships are among the factors most closely related to adolescent life satisfaction ${ }^{11,24}$.

In several dietary restraint studies, participants have been divided into classes of chronic dieters and nondieters based on a conventional cutoff point. This method has been criticized since dividing study participants into dichotomous groups may lead to a loss of variability and may mask associations of different behavioral combinations ${ }^{4,20,25}$. Thus, some authors have used empirical classifications, such as cluster analysis or latent class analysis, to examine subgroups of dieters and weight management strategies in samples of female adolescents ${ }^{4,25}$, adults and emerging adults of both genders ${ }^{20,26}$ and among young males ${ }^{22}$. However, to the best of our knowledge, only one available study has considered a sample of adolescents of both genders ${ }^{13}$. This study distinguished three profiles in Finnish adolescents: unbalanced weight control, adverse habits and healthy lifestyle. Therefore, more research is needed in order to distinguish different profiles of adolescents of both genders according to their dietary restraint behavior. Although girls and female adolescents are more prone to dietary restraint ${ }^{16}$ and usually have higher values of restrained eating than boys ${ }^{7}$, the relationship between higher BMI and dietary restraint exists in adolescents of both genders ${ }^{7}$. Furthermore, recent studies have suggested that "the gap between male and female individuals in dietary restraint may be narrowing ${ }^{\prime 22,23}$.

In this context, the objectives of this study were: a) to identify adolescent profiles based on dietary restraint behavior $b$ ) to determine if these profiles differed in terms of adolescent diet quality, nutritional status, life satisfaction, and satisfaction with family life and food-related life, and c) to determine if these profiles differed in terms of family characteristics, mother dietary restraint, diet quality and nutritional status.

\section{MATERIAL AND METHODS Study sample and procedure}

The study was approved by the Ethics Committee of Universidad de La Frontera (Protocol number 005/2016, Chile) and was conducted with 470 families with at least one child between 10 and 17 years of age. Participants were recruited from seven schools that serve socioeconomically diverse populations in Temuco, Chile. Directors in each school signed authorization letters to allow research to be conducted with their students and provided a list of students from fifth grade upwards along with their mothers' telephone numbers. Mothers were contacted by trained interviewers who explained the objectives of the study and the confidential treatment of the information obtained. Mothers were provided detailed information about the questionnaires and asked if they and one of her children between 10 and 17 years of age wanted to participate in the study. Interviews were conducted in the participants' homes. After mothers had signed written informed consents and adolescents had signed assent forms, both were interviewed individually with no other family members present. The anonymity of the respondents was ensured. The study was conducted between June and December 2016. A pilot test of the questionnaires was conducted with 20 mother-adolescent dyads following this recruitment method.

\section{Measures}

Mother and adolescent questionnaires included the following scales:

- Revised Restraint Scale (RRS) ${ }^{1,27}$ : the RRS is a 10-item scale that consists of two subscales: Diet concern (DC) (e.g. "Do you give too much time and thought to food?") and Weight fluctuations (WF) (e.g. "What is the 
maximum amount of weight (in kilos) you have ever lost within 1 month?"). Options for the responses are on 4-point Likert scale for the DC subscale and 5-point Likert scale for the WF subscale. Higher scores indicate stricter dietary restraint. In this study, the Spanish version of the RRS was used as it showed adequate levels of internal consistency for each subscale in a previous study conducted in Chile examining a sample of female adolescents $^{28}$. In this study, the DC ( $\omega$ mothers $=0.74$, $\omega$ adolescents $=0.67)$ and $W F(\omega$ mothers $=0.71, \omega$ adolescents $=0.69)$ subscales showed acceptable internal consistency.

- Adapted Healthy Eating Index (AHEI): the AHEI is an adaption of the US-HEI ${ }^{29}$ developed by Norte and $\mathrm{Ortiz}^{30}$ for Spanish speaking populations. Respondents were asked to provide information on their frequency of consumption for nine food groups. Each group received a score, ranging from 0 to 10 according to the degree of compliance with food recommendations ${ }^{30}$. The AHEI score was calculated by adding the score obtained for each of the variables, with a maximum of 100 points. Scores above 80 are indicative of a "healthy" diet; scores between 51 and 80 correspond to a diet that "requires changes"; scores below 50 correspond to "unhealthy" $\operatorname{diets}^{29}$.

\section{Adolescents responded to the following scales}

- Satisfaction with Life Scale (SWLS) ${ }^{31}$ : The SWLS is a scale consisting of five items grouped into a single dimension that is used to evaluate the overall cognitive judgments about a person's own life (e.g. "In most ways my life is close to my ideal").

- Satisfaction with Food-related Life (SWFoL) $)^{32}$ : The SWFoL is a scale consisting of five items grouped into a single dimension that is used to evaluate a person's overall assessment of their food and eating habits (e.g. "Food and meals are positive elements").

- Satisfaction with Family Life (SWFaL) $)^{33}$ : The SWFaL is a modified version of the SWLS ${ }^{31}$, to assess the conscious, cognitive judgments of one's family life.

Respondents were asked to indicate their degree of agreement with the five statements of the SWLS, SWFoL and SWFaL scales using a 6-level Likert scale (1: completely disagree; 6: completely agree). This study used the Spanishlanguage versions of the SWLS ${ }^{34}$, SWFoL ${ }^{34}$ and SWFaL ${ }^{35}$. SWLS, SWFoL and SWFaL scores are the sum of the five items of each scale with higher scores indicating higher satisfaction. In this study, the SWLS $(\omega=0.93)$, SWFoL $(\omega=$ $0.91)$ and SWFaL $(\omega=0.94)$ showed good levels of internal consistency. The discriminant validity of the three scales was previously demonstrated in samples of undergraduate students and adolescents in Chile ${ }^{11,35}$.

Mothers and children were asked about their age. Mothers were asked about family structure, the frequency of shared family meals and the number of family members.
Mothers and adolescents were asked to indicate their own approximate weight and height in order to determine their $\operatorname{BMI}\left(\mathrm{kg} / \mathrm{m}^{2}\right)$. The combination of the education level and the occupation of the head of household in a matrix determined family socioeconomic status (SES) ${ }^{36}$.

\section{Data analyses}

A latent class analysis (LCA) was used to estimate the number of classes associated with adolescent dietary restraint behavior. LCA has proven to be a useful tool in clustering samples of different age and gender composition according to their dieting and weight management behaviors ${ }^{4,13,25,26}$.

A LCA was applied using the Latent Gold 5.1 statistics software (Statistical Innovations Inc.). The optimal number of classes was selected ${ }^{37}$ based on log likelihood (LL) and the Bayesian information criterion (BIC), where lower scores indicate a better fit.

We distinguished only two latent classes, so in order to evaluate differences between them, a Student t-test considering independent samples was applied for continuous variables. A Chi-square test was applied for discrete variables. The results were analyzed using SPSS v. 23.0.

\section{RESULTS Sample description}

470 mother-adolescent dyads participated in the study. The mean age of mothers was 41.4 years and the mean age for adolescents was 13.3 years. $52.3 \%$ of the adolescents were female. Table 1 shows the sociodemographic characteristics of the sample. There was a higher proportion of adolescents living in dual-headed households and belonging to the lower-middle SES. The average AHEI score for mothers and adolescents denoted diets that required changes.

According to the criteria of the World Health Organization $(\mathrm{WHO})^{38}$, a high proportion of mothers were overweight. According to the criteria of the $\mathrm{WHO}^{39}$ and the Technical Norm of Nutritional Evaluation of the Chilean Ministry of Health for children aged 5 to 19 years ${ }^{40}$, a high proportion of adolescents were in the normal BMI range. Average RRS scores from adolescents and mothers were close to the median scores of the scale (adolescents $=16$, mothers $=24$ ). The SWFoL, SWFaL and SWLS scores indicated that adolescents were satisfied with their food-related life, family life and their life in general.

\section{Latent classes}

An initial run of 1-5 clusters was analyzed using the 10 RRS items. The two-cluster model appeared to be the best fit because it had the lowest BIC value. Nevertheless, the LL value for the five-cluster model was the lowest. We also considered the classification error percentage, which led us to choose the two-cluster model (Table 2): Non-dieters (latent class 1) and dieters (latent class 2). This LCA solution with two latent classes (Table 3) shows that the 10 items of the RRS significantly contributed to the overall solution, which is indicated by the information content value (Wald statistic). Table 3 shows the class profile related to each RRS item. 
Table 1. Socio-demographic characteristics, average Adapted Healthy Eating Index (AHEI) score, diet variety score, body mass index (BMI), frequency of family meals, and average scores of dietary concern (DC), weight fluctuation (WF) subscales and Revised Restraint Scale (RSS), Satisfaction with food-related (SWFoL), Satisfaction with family life (SWFaL) and Satisfaction with life (SWLS) scales of the sample.

\section{Characteristic}

Total sample

$(n=470)$

Maternal age

$41.4(7.3)$

Children [Mean (SD)]

$13.3(2.3)$

Number of family members [Mean (SD)]

$4.1(1.3)$

Family structure (\%)

Dual-headed household

63.8

Single-headed household

36.2

Socioeconomic status (\%)

High and upper-middle

16.7

Middle-Middle

20.3

Lower-Middle

33.1

Low

23.6

Very low

6.3

AHEI [Mean (SD)]

Mothers

$64.5(14.3)$

Adolescents

61.1 (14.6)

Diet variety from AHEI [Mean (SD)]

Mothers

$4.0(2.6)$

Adolescent

$4.1(2.6)$

Number of days a week families eat together [Mean (SD)]

Breakfast

$4.2(2.8)$

Lunch

$4.4(2.6)$

Dinner

$3.9(3.2)$

BMI category- children (\%) ${ }^{2}$

Undernourished ( $\leq-2 \mathrm{SD})$

6.8

Underweight ( $\leq-1$ to $-1.9 \mathrm{SD})$

13.4

Normal range (+0.9 to $-0.9 \mathrm{SD})$

56.2

Overweight $(\geq+1$ to +1.9 SD)

18.1

Obesity $(\geq+2$ SD)

BMI category- mothers (\%)

Normal range

27.6

Overweight

42.1

Obesity

30.2

Children

DC [Mean (SD)]

$10.5(3.5)$

WF [Mean (SD)]

6.7

RRS [Mean (SD)]

Mothers

DC [Mean (SD)]

$14.5(4.0)$

WF [Mean (SD)]

$9.5(3.2)$

RRS [Mean (SD)]

$24.0(5.8)$

Adolescent SWFoL [Mean (SD)]

$22.6(6.3)$

Adolescent SWFaL [Mean (SD)]

$24.1 \quad(5.7)$

Adolescent SWLS [Mean (SD)]

23.9 (5.6) 
Table 2. Summary of latent class cluster models.

\begin{tabular}{|c|c|c|c|c|c|}
\hline & $\mathbf{L L}^{+}$ & $\operatorname{BIC}(\mathrm{LL})^{\ddagger}$ & Npar ${ }^{\S}$ & $\mathbf{L}^{2}$ & Classification Error \\
\hline 1- Cluster & -5563.9578 & 11343.2613 & 35 & 6094.2051 & 0.00 \\
\hline 2- Cluster & -5283.8843 & 10992.3072 & 69 & 5534.0582 & 0.08 \\
\hline 3- Cluster & -5195.9826 & 11025.6967 & 103 & 5358.2548 & 0.10 \\
\hline 5- Cluster & -5084.4858 & 11221.0888 & 171 & 5135.2610 & 0.13 \\
\hline
\end{tabular}

${ }^{+} \mathrm{LL}=$ Log-likelihood.

${ }^{\ddagger} \mathrm{BIC}(\mathrm{LL})=$ Bayesian information criterion based on the log-likelihood.

${ }^{\S}$ Npar $=$ Number of parameters.

Latent Class 1: represented $52.4 \%$ of the total sample. Adolescents from Class 1 were likely to respond "never" to all items on the DC subscale, as well as all items on the WF subscale.

Latent Class 2: represented $47.56 \%$ of the sample. With regard to the DC subscale, adolescents from Class 2 were likely to respond "rarely" or "sometimes" to "How often are you dieting?", "moderately" or "very much" to "Would a weight fluctuation of 2.5 kilos affect the way you live your life?", "rarely" or "often" to "Do you eat sensibly in front of others and splurge alone?", "rarely" to "Do you give too much time and thought to food?, "often" or "always" to "Do you have feelings of guilt after overeating?", and "moderately" or "extremely" to "How conscious are you what you are eating?". Regarding items from the WF subscale, adolescents from this class were likely to respond that they had lost a maximum of between 2.5 and $5 \mathrm{~kg}$ within a month, had gained a maximum of between 0.5 and $1 \mathrm{~kg}$ within a week, fluctuated between 0.5 and $1 \mathrm{~kg}$ in a typical week and had a maximum weight between 3-5 kg or 5-10 kg over their desired weight.

The significantly higher scores in WF, DC and on the RRS (Table 4) among "dieters" (class 2) compared to "nondieters" (class 1) was consistent with the above-described characteristics using LCA. Given that the RRS scores are commonly used to classify individuals into chronic dieters and non-dieters (usually using median scores) 1 and the median score of the RRS of the studied sample was 16, it is noteworthy that the RRS mean score of "dieters" was above the median score. Thus, adolescents from this class can be considered chronic dieters.

"Dieters" $(p<0.001)$ had a significantly higher mean age than "non-dieters" ( $p<0.05)$ (Table 4). Families of "nondieters" had dinner together significantly more often during the week than families of "dieters" ( $p<0.05)$. Although mothers from the two classes did not differ in their DC scores (N.S), mothers of "dieters" had higher WF scores $(p<0.001)$ and also on the RRS $(p<0.05)$. "Non-dieters" had higher scores on the SWLS and the SWFoL $(p<0.05)$.

"Non-dieters" had a greater proportion of underweight adolescents (Table 5), whereas "dieters" had a higher proportion of overweight and obese adolescents $(p<0.001)$. "Non-dieters" had a higher proportion of normal weight mothers, whereas "dieters" had a higher proportion of obese mothers $(p<0.05)$.

No significant differences between classes were found for the rest of the variables examined in this study.

\section{DISCUSSION}

This study focused on identifying adolescent profiles based on dietary restraint behavior to determine if these profiles differed in terms of adolescent diet quality, nutritional status, life satisfaction or satisfaction with family life and food-related life, and to determine if these profiles differed in terms of family characteristics, maternal dietary restraint, diet quality and nutritional status. The results of the LCA yielded two classes: "non-dieters" (class 1, 52.44\%) and "dieters" (class 2, 47.56\%). Dieters had a higher mean age, a higher proportion of overweight and obesity and lower scores on the satisfaction with life and food-related life. Families from the dieters class had a lower frequency of family dinners. Their mothers had higher weight fluctuations and higher rates of obesity.

During adolescence, body image and dieting concerns are common and often associated with an increased desire to be accepted as having attained the idealized cultural image of beauty, which is often associated with thin or lean bodies $^{6}$. This leads adolescents of both genders to adopt behaviors related to dietary restraint ${ }^{16}$. This is the first study that has identified adolescent profiles of both genders based on participant responses to the RRS using LCA. Contrary to what was expected, only two adolescent profiles were detected. This finding contradicts the results obtained by $\mathrm{Kachi}^{25}$ in Japan and Balantekin et $\mathrm{al}^{4}$ in the U.S. which used LCA on samples of female adolescents as well as those reported by Peterson et $\mathrm{al}^{26}$ with an adult sample of both 
Table 3. Indicator variables by class.

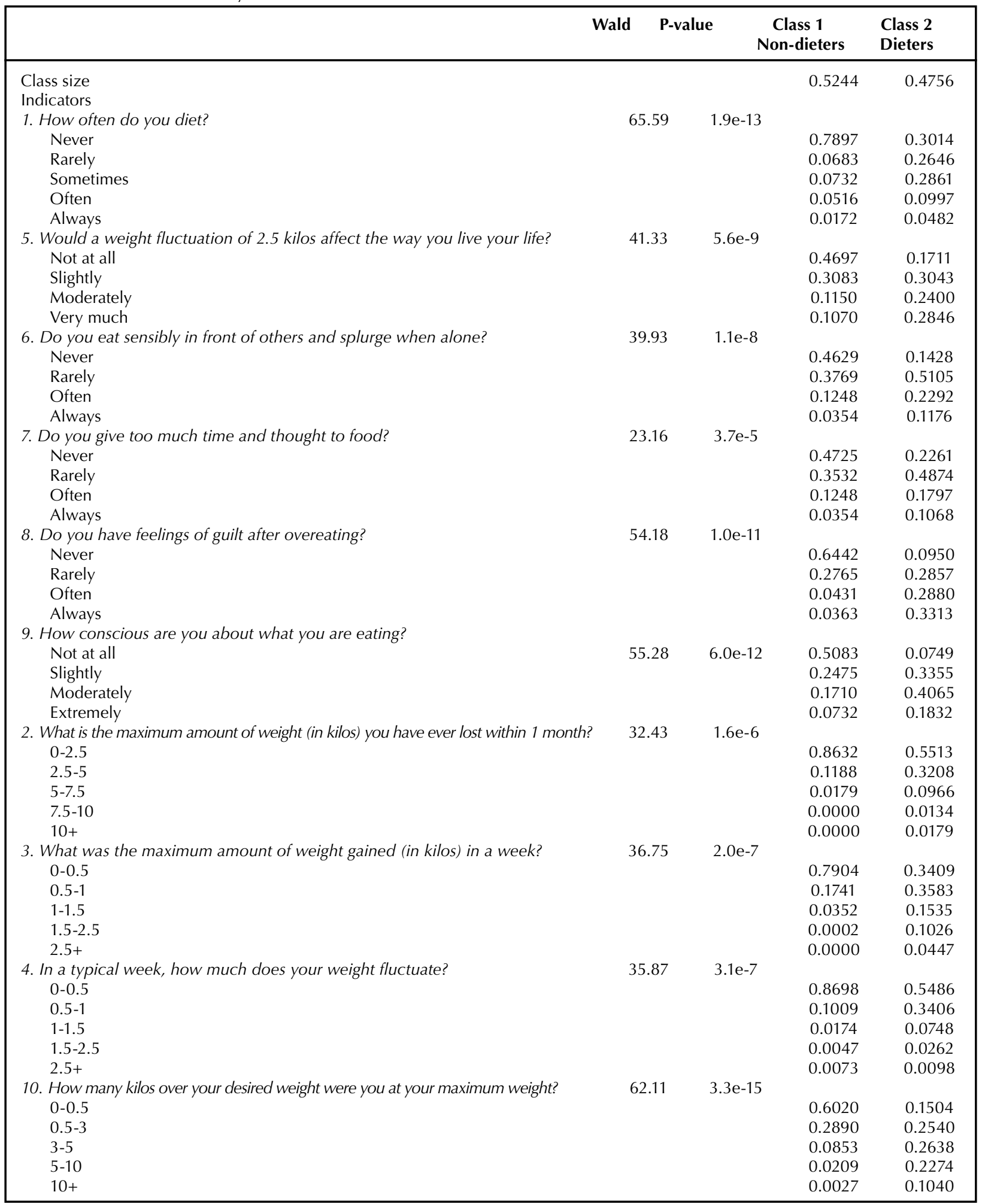

The items are presented according to the ERA subscale to which they belong. Items 1, 5, 6, 7, 8 and 9 belong to the Diet Concern subscale. Items 2, 3, 4 and 10 belong to the weight fluctuation subscale. 
Table 4. Differences between latent classes according to adolescent age, frequency of family meals, Satisfaction with Life (SWLS), food-related life (SWFaL), Diet Concern (DC), Weight Fluctuation (WF) and Revised Restraint Scale (RRS) scores.

\begin{tabular}{|c|c|c|c|c|}
\hline & $\begin{array}{l}\text { Class } 1 \\
\text { Dieters }\end{array}$ & $\begin{array}{l}\text { Class } 2 \\
\text { Non-dieters }\end{array}$ & $\mathbf{t}$ & P-value \\
\hline Adolescent age & 12.7 & 13.9 & -5.581 & 0.000 \\
\hline Number of days a week families have dinner together & 4.3 & 3.6 & 2.213 & 0.027 \\
\hline \multicolumn{5}{|l|}{ Adolescent } \\
\hline DC & 9.9 & 15.2 & -20.904 & 0.000 \\
\hline WF & 5.2 & 8.3 & -15.188 & 0.000 \\
\hline RRS & 15.1 & 23.5 & -26.866 & 0.000 \\
\hline \multicolumn{5}{|l|}{ Mothers } \\
\hline DC & 14.3 & 14.8 & -1.508 & 0.132 \\
\hline WF & 8.9 & 10.0 & -3.580 & 0.000 \\
\hline RRS & 23.3 & 24.9 & -3.002 & 0.003 \\
\hline Adolescent SWLS & 24.7 & 23.1 & 2.992 & 0.003 \\
\hline Adolescent SWFoL & 23.4 & 21.7 & 2.914 & 0.004 \\
\hline
\end{tabular}

*P value corresponds to independent sample t-test.

Table 5. Differences (\%) between latent classes according to mother and adolescent BMI category.

\begin{tabular}{|c|c|c|}
\hline & $\begin{array}{l}\text { Class } 1 \\
\text { Dieters }\end{array}$ & $\begin{array}{c}\text { Class } 2 \\
\text { Non-dieters }\end{array}$ \\
\hline BMI category- mothers & \multicolumn{2}{|c|}{$p<0.005$} \\
\hline Normal range & 32.4 & 22.3 \\
\hline Overweight & 44.0 & 40.0 \\
\hline Obesity & 23.6 & 37.7 \\
\hline BMI category- children & \multicolumn{2}{|c|}{$p<0.001$} \\
\hline Undernourished & 8.4 & 5.0 \\
\hline Underweight & 18.8 & 7.3 \\
\hline Normal range & 55.6 & 56.8 \\
\hline Overweight & 14.0 & 22.7 \\
\hline Obesity & 3.2 & 8.2 \\
\hline
\end{tabular}

*P-value corresponds to the (bilateral) asymptotic significance obtained in the Pearson's Chi squared Test.

genders in the U.S. All of these authors identified three or more different profiles in terms of dieting behaviors. Kachi ${ }^{25}$ identified "unhealthy dieters" (27\%), "healthy dieters" (39\%) and "non-dieters" (34\%). Balantekin et $\mathrm{al}^{4}$ identified the following profiles: "non-dieters" (26\%), "lifestyle" (16\%, characterized by a high probability of reporting increasing exercise and eating more fruits and vegetables for weight control, both health-promoting lifestyle changes), "dieters" 
(43\%), and "extreme dieters" (17\%). Peterson et al ${ }^{26}$ identified profiles characterized by "dietary restraint only" (51\%), "low dietary restraint" (27\%) and "dietary restraint plus psychopathology" (22\%). In addition, our results contradict previous findings reported in Chile using the RRS that used a hierarchical cluster analysis and identified four profiles in a sample of undergraduate students of both genders ${ }^{20}$ : "unconcerned about diet and weight fluctuations" (53.8\%), "concerned about dieting" (18.7\%), "concerned about weight fluctuations" $(17.1 \%)$, and "concerned about diet and weight fluctuations" (10.6\%). Three profiles were also identified in a sample of male undergraduate students ${ }^{21}$ : "unconcerned about diet and weight fluctuations" (40.3\%), "concerned about diet and weight fluctuations" (37.0\%) and "concerned about weight fluctuations" (22.7\%). These differences may be related to the gender and age composition of the samples, cultural factors and/or the instrument used to measure dietary restraint. All of these variables require further research.

It is worth noting that the RRS mean scores of the "nondieters" and "dieters" classes match the cutoff commonly used to classify "non-dieters" and "chronic dieters"1. Regardless, the results obtained using LCA allowed the more common diet concern behaviors and weight fluctuations in the "dieters" class to be identified (Table 3). Contrary to previous studies associating overweight, obesity and dietary restraint with a low diet quality $1^{3,16}$, adolescents and mothers from "dieters" and "non-dieters" did not differ in their diet quality. Therefore, the higher presence of overweight and obese adolescents and obese mothers in the "dieters" class may be explained by considering other determinants of obesity, such as physical activity ${ }^{15}$, which deserves more attention in future studies. Nevertheless, these results confirm the need for Chilean families to modify their eating habits $3,11,14,15$, since both classes had low AHEI scores.

The greater proportion of overweight and obese adolescents and obese mothers in the "dieters" class is consistent with studies that have linked higher BMIs to increased dietary restraint in adolescents and adults of both genders ${ }^{21,22,28}$. This may be the case of unsuccessful dieters, who are characterized by high restraint and a high tendency toward overeating ${ }^{20}$. Nevertheless, other authors have suggested that a higher BMI would not only be an outcome of restrained eating, but may also predict restrained eating in adolescents of both genders ${ }^{4,7}$. Thus, further research is needed to understand the association between BMI and dietary restraint in mothers and their adolescent children. However, the higher proportion of overweight and obese adolescents and obese mothers in the "dieters" class could explain the use of food restriction by these mothers. Berge et $\mathrm{al}^{17}$ found that when the parent and the adolescent were both overweight/obese, the parent engaged in high levels of food restriction, which may induce both overeating and dietary restraint in the adolescent ${ }^{10}$. In a sample of young children, Haycraft et al ${ }^{9}$ similarly found that overweight/obese mothers reported controlling their children's eating more often, but modeled healthy eating less. These behaviors may be potential pathways for the intergenerational transmission of obesity and dietary restraint from mother to child9.

Regarding adolescent well-being, the significantly lower SWLS scores from the "dieters" class confirm previous findings showing that lower levels of life satisfaction are associated with dietary restrain ${ }^{20}$ and obesity ${ }^{22}$ in university students. Lower SWFoL scores of the "dieters" class is also supported by studies that have reported that dietary restraint is associated with lower levels of well-being in the food domain in samples of university students ${ }^{20,22}$. However, the lack of statistical differences between the "dieters" and "non-dieters" classes on the SWFaL would confirm that dietary restraint is not associated with satisfaction with family life ${ }^{23}$, although family eating habits ${ }^{6,17}$, food-related parenting practices ${ }^{17}$ and parents' dieting behaviors ${ }^{5}$ have been related to weight control behaviors in adolescents. In this regard, Schnettler, Miranda-Zapata et a ${ }^{23}$ explain these results by suggesting that adolescent assessment of family life satisfaction does not consider either food-related or dietary aspects. However, another possible explanation may be related to the mean ages of the classes (higher mean age of "dieters") given that it has been reported that adolescent well-being decreases during adolescence in both genders, but not in the same way as it does across all life domains ${ }^{24}$.

Another unexpected result was the lack of statistical differences in the gender composition of both classes, which contradicts previous studies that found that female adolescents are more likely to engage in dietary restraint than male adolescents ${ }^{7,16}$. However, our findings confirm previous studies that have suggested that "the gap between male and female individuals in dietary restraint may be narrowing" 22,23 . Our findings may also be related to the increasing rates of obesity and overweight among children and adolescents of both genders ${ }^{8}$ worldwide, as an increased weight status or BMI has been linked to increased dieting behaviors in adolescents of both genders 7 . Therefore, our results support the need for further research on dietary restraint in male samples ${ }^{21,22,23}$, but especially in male adolescent samples.

Regarding family meals, our results contradict evidence showing that a high frequency of family meals is associated with healthier diets ${ }^{12}$. Even though "non-dieters" had a higher frequency of shared dinners with their family than "dieters", the two classes did not differ in their diet quality. However, the greater frequency of family dinners in the "non-dieters" is in line with studies that have reported that a higher frequency of family meals is associated with a lower likelihood of obesity or overweight ${ }^{13}$ as well as higher wellbeing in adolescents $\mathrm{s}^{3,13,14,15}$. This is because more frequent family meals lead to more connected, communicative and supportive families, which in turn may lead to more positive experiences ${ }^{12}$. Also, our results confirm that a higher frequency of family meals is associated with a lower likelihood of dietary restraint in adolescents ${ }^{6,12}$. Therefore, frequent family meals should be promoted in families with 
adolescent children to improve their well-being and also to prevent dietary restraint behaviors.

In addition, the main difference between the mothers of the "dieters" and "non-dieters" classes was the higher WF score among mothers in the "dieters" class. Therefore, it is possible that, regardless of the mother's diet concern, the mother's weight fluctuations are related to their adolescent children's exercise of dietary restraint, regardless of gender. Although this result contradicts the previous findings that the eating characteristics of male adolescents are unrelated to those of their mothers ${ }^{10}$, it partially agrees with the results reported by Francis and Birch ${ }^{18}$, who found that mothers that were more preoccupied with their own weight made more attempts to influence their daughters' weight, thereby leading them to practice dietary restraint. This may also be the case with male and female adolescents in the "dieters" class due to the increased prevalence of overweight and obesity in adolescents of both genders ${ }^{8}$. However, our results support those reported by van den Berge et al ${ }^{17}$, specifically the finding that greater maternal concern regarding weight is related to an increase in weight loss attempts in adolescents of both genders.

The main limitations of this study include its crosssectional design and the non-probabilistic nature of the sample, which limits the generalization of our results. Responses may also have been affected by social desirability as all data were self-reported. Indeed, self-reported eating habits may be affected by an overestimation of the frequency of healthy food consumption and an underestimation of the frequency of unhealthy food consumption, especially in the "dieters" class as reported in previous studies ${ }^{4}$. The same underestimation may occur in self-reported weight. Another potential limitation is that we did not consider the ways mothers pressure their children to be thin or the food-related parenting practices used to promote weight loss. Since the sample included adolescents from both dual-headed and single-headed households, the influence of fathers was also not measured. All of these variables should be addressed in future studies.

Despite these limitations, this study shows that there is a high prevalence of dietary restraint in adolescents regardless of gender, which is concerning given the increasing prevalence of obesity and overweight in adolescents in Chile and the prevalence of low diet quality at the national level. Dietary restraint in the studied sample was related to higher adolescent and mother BMls, greater mother weight fluctuations, a lower frequency of family meals and lower levels of life satisfaction and satisfaction with food-related life in adolescents. Therefore, interventions intended to reduce obesity/overweight and dietary restraint in adolescents, as well as those aimed at improving their levels of subjective well-being, must include both the mother and the adolescent child, regardless of gender.

Acknowledgments: This study was funded by Conicyt, Fondecyt Project $n^{\circ}$ 1160005. The authors declared no potential conflicts of interest with respect to the research, authorship, and/or publication of this article.

\section{REFERENCES}

1. Herman C, Polivy J. Stunkard, AJ. ed. Restrained eating. WB., Sanders, London 1980 pp 208-225.

2. Schaumberg K, Anderson DA, Anderson LM, Reilly EE, Gorrell S. Dietary restraint: what's the harm? A review of the relationship between dietary restraint, weight trajectory and the development of eating pathology. Clin Obes. 2016; 6: $89-100$.

3. Schnettler B, Grunert KG, Lobos G, Miranda-Zapata E, Denegri $M$, Ares $G$, Hueche $C$. A latent class analysis of family eating habits in families with adolescents. Appetite. 2018; 129: 37-48 .

4. Balantekin KN, Birch LL, Savage JS. Patterns of weight-control behavior among 15 year old girls. Int J Eat Disord. 2015; 48: 589-600.

5. Arroyo A, Segrin C, Andersen KK. Intergenerational transmission of disordered eating: Direct and indirect maternal communication among grandmothers, mothers, and daughters. Body Image. 2017; 20:107-115.

6. Suelter CS, Schvey N, Kelly NR, Shanks M, Thompson KA, Mehari $R$, et al. Relationship of pressure to be thin with gains in body weight and fat mass in adolescents. Pediatr Obes. 2018; 13: 14-22.

7. Forrester-Knauss C, Perren S, Alsaker FD. Does body mass index in childhood predict restraint eating in early adolescence? Appetite. 2012; 59: 921-926.

8. NCD Risk Factor Collaboration. Worldwide trends in bodymass index, underweight, overweight, and obesity from 1975 to 2016: a pooled analysis of 2416 population-based measurement studies in 128. 9 million children, adolescents, and adults. Lancet. 2017; 390: 2627-2642.

9. Haycraft E, Karasouli E, Meyer C. Maternal feeding practices and children's eating behaviours: A comparison of mothers with healthy weight versus overweight/obesity. Appetite. 2017; 116: 395-400.

10. Matton A, Goossens L, Braet C, Van Durme K. Continuity in primary school children's eating problems and the influence of parental feeding strategies. I Youth Adolesc. 2013; 42: 5266.

11. Schnettler B, Lobos G, Miranda-Zapata E, Denegri M, Ares $G$, Hueche C. Diet quality, satisfaction with life, family life and food-related life across families: A cross-sectional study with mother-father-adolescent triads. Int I Environ Res Public Health. 2017; 14: 1313.

12. Berge JM, MacLehose $R$, Loth KA, Eisenberg M, Bucchianeri $M M$, Neumark-Sztainer D. Parent conversations about healthful eating and weight: associations with adolescent disordered eating behaviors. JAMA Pediatr. 2013; 167: 746-753.

13. Jääskeläinen A, Nevanperä N, Remes J, Rahkonen F, Järvelin $M R$, Laitinen J. Stress-related eating, obesity and associated behavioural traits in adolescents: a prospective populationbased cohort study. BMC Public Health. 2014; 14: 321.

14. Schnettler B, Grunert KG, Lobos G, Miranda-Zapata E, Denegri $M$, Hueche C. Maternal food-related practices, quality of diet, and well-being: Profiles of Chilean mother-adolescent dyads. I Nutr Educ Behav. 2018; 50: 776-787.

15. Schnettler B, Miranda H, Miranda-Zapata E, Lobos G, Denegri M, Lapo M, Ares G, Hueche C. Diet quality and satisfaction with different domains of life in single-and dual-headed households: Comparing mother-adolescent dyads. Child Youth Serv Rev. 2018; 89: 124-131. 
16. Ramos P, Brooks F, García-Moya I, Rivera F, Moreno, C. Eating habits and physical activity in dieter and non-dieter youth: A gender analysis of English and Spanish adolescents. Soc Sci J. 2013; 50: 575-582.

17. Berge JM, Meyer CS, Loth K, MacLehose R, Neumark-Sztainer, $D$. Parent/adolescent weight status concordance and parent feeding practices. Pediatrics. 2015; 136: e591-e598.

18. Francis $L A$, Birch LL. Maternal influences on daughters' restrained eating behavior. Health Psychol. 2005; 24: 548554.

19. van den Berg PA, Keery H, Eisenberg M, Neumark-Sztainer $D$. Maternal and adolescent report of mothers' weight-related concerns and behaviors: Longitudinal associations with adolescent body dissatisfaction and weight control practices. J Pediatr Psychol. 2010; 35: 1093-1102.

20. Schnettler B, Miranda H, Sepúlveda J, Peterson L, Etchebarne $S$, Lobos G, Mora M, Denegri M, Grunert K. Dietary restraint and subjective well-being in university students in Chile. Nutr Hosp. 2014; 30: 453-461.

21. Orellana L, Grunert KG, Sepúlveda J, Lobos G, Denegri $M$, Miranda H. Adasme-Berríos C. Mora M. Etchebarne S. Salinas-Oñate N. Schnettler B. Dietary restraint and selfdiscrepancy in male university students. Eat Behav. 2016; 21: 123-128.

22. Schnettler B, Grunert KG, Orellana L, Sepúlveda J, Miranda $H$, Lobos $G$, et al. Dietary restraint, life satisfaction and selfdiscrepancy by gender in university students. Suma Psicol. 2017; 24: 25-33.

23. Schnettler B, Miranda-Zapata E, Grunert KG, Lobos G, Denegri $M$, Hueche $C$. Weight fluctuation and diet concern negatively affect food-related life satisfaction in Chilean male and female adolescents. Front Psychol. 2018; 9: 1013.

24. González-Carrasco M, Casas F, Viñas F, Malo S, Gras ME, Bedin L. What leads subjective well-being to change throughout adolescence? An exploration of potential factors. Child Indic Res. 2017; 10: 33-46.

25. Kachi Y. Latent structure of dieting among female high-school students in Japan. Pers Individ Dif. 2010; 48: 11-15.

26. Peterson CB, Crosby RD, Wonderlich SA, Mitchell JE, Crow SI, Engel S. Predicting group cognitive-behavioral therapy outcome of binge eating disorder using empirical classification.
Behav Res Therapy. 2013; 51: 526-532.

27. Herman C, Mack D. Restrained and unrestrained eating. I Pers.1975; 43: 647-660.

28. Silva J. Internal consistency and factorial validity of a Spanish version of the Revised Restraint Scale. Rev Chil Nutr. 2010; 37: 41-49.

29. Kennedy ET, Oh/s J, Carlson S, Fleming K. The healthy eating index: design and applications. I Am Diet Assoc. 1995; 95: 1103-1108.

30. Norte Al, Ortiz R. Spanish diet quality according to the healthy eating index. Nutr Hosp. 2011; 26: 330-336.

31. Diener E, Emmons $R$, Larsen $R$, Griffin $S$. The satisfaction with life scale. J Pers Assess. 1985; 49: 71-75.

32. Grunert $K$, Dean D, Raats $M$, Nielsen N, Lumbers M. A measure of satisfaction with food-related life. Appetite. 2007; 49: 486-493.

33. Zabriskie R, McCormick B. Parent and child perspectives of family leisure involvement and satisfaction with family life. I Leis Res. 2003; 35: 163-189.

34. Schnettler B, Miranda H, Sepúlveda J, Denegri M. Satisfaction with food and life, an exploratory study among students in la Frontera University, Temuco-Chile. Psicol Soc. 2011; 23 : 426-435.

35. Schnettler B, Miranda-Zapata E, Grunert KG, Lobos G, Denegri $M$, Hueche $C$, Poblete $H$. Life satisfaction of university students in relation to family and food in a developing country. Front Psychol. 2017; 8: 1522.

36. Adimark. Socioeconomic Map of Chile. http://www.adimark. cl. (accessed on 30/Dec/2015).

37. Vermunt JK. Applications of latent class analysis in social science research. Lec Notes Comput Sci. 2003; 2111: 22-36.

38. WHO EC. Appropriate body-mass index for Asian populations and its implications for policy and intervention strategies. Lancet 2004; ; 363:157-163

39. WHO (World Health Organization). Child Growth and Development. http://www.who.int/childgrowth/en/ (accessed 12/Jun/2018)

40. MINSAL (Ministerio de Salud de Chile). Technical guidelines for the control of integral health of adolescents. http://web. minsal.cl/wp-content/uploads/2015/09/OT-CONTROL-DESALUD-INTEGRAL-FINAL.pdf (accessed 17/Jun/2016). 